\title{
Combined Precipitation/Flocculation Method for Nutrient Recovery from Greenhouse Wastewater
}

\author{
C. Siobhan Dunets and Youbin Zheng ${ }^{1}$ \\ School of Environmental Science, University of Guelph, 50 Stone Road East, \\ Guelph, ON N1G 2W1, Canada
}

Additional index words. phosphate, wastewater treatment, phosphorus removal, calcium phosphate precipitation, guar gum, cationic starch, chitosan

\begin{abstract}
Phosphorus (P) pollution from greenhouse wastewater is currently a major issue. A treatment method that can efficiently remove $P$ concentrations ([P]) that fluctuate between greenhouse systems and throughout the year is required. An ideal method would also recover nutrients in a reuseable form. A combined precipitation/ flocculation process incorporating addition of lime and a biodegradable flocculant (guar gum, cationic starch, or chitosan) was investigated for providing optimized $P$ removal and recovery. Effectiveness of this process was evaluated in simulated wastewater of low and high alkalinity, as well as real greenhouse wastewater. Precipitation via lime addition reduced total $P$ to below $1 \mathrm{mg} \cdot \mathrm{L}^{-1}$ in low-alkalinity simulated wastewater, but high alkalinity slightly inhibited separation. This inhibition was overcome by flocculation via guar gum or cationic starch addition, which improved separation efficiency and reduced separation time, although chitosan was ineffective as a flocculant. The precipitation/ flocculation method was found to be effective for treating real greenhouse wastewater, although effectiveness varied with variation in wastewater composition. Recovered precipitate contained $57.4 \mathrm{~g} \cdot \mathrm{kg}^{-1} \mathrm{P}$ as well as high levels of $\mathrm{Ca}, \mathrm{Mg}, \mathrm{K}, \mathrm{Fe}$, and $\mathrm{Zn}$. This study demonstrates a $P$ separation process incorporating lime and biodegradable flocculants could provide a means of reducing $P$ in greenhouse wastewater below a $1 \mathrm{mg} \cdot \mathrm{L}^{-1}$ regulatory limit in a settling time of less than 30 minutes, while simultaneously recovering $P$ and other nutrients in a form that could be reused as fertilizer. An evaluation of viability of full-scale application of this technology is now warranted.
\end{abstract}

Recent legislation in North America suggests stricter control will soon be put on the release of nitrogen and P-laden greenhouse wastewater into the environment (OGVG, 2012). Unlike nitrogen, conventional treatment systems for greenhouse wastewater, namely constructed wetlands, cannot effectively remove P (Vymazal, 2007). Concentrations of orthophosphate-derived $\mathrm{P}\left(\mathrm{PO}_{4}-\mathrm{P}\right)$, the most common form of $\mathrm{P}$ in used greenhouse nutrient solution (which will be referred to as greenhouse wastewater), are typically around 30-60 mg. $\mathrm{L}^{-1}$ (Gagnon et al., 2010; MOE, 2012; Prystay and Lo, 2001), but can be as high as $370 \mathrm{mg} \cdot \mathrm{L}^{-1} \mathrm{P}$ (Saxena and Bassi, 2012). In Ontario, a total $P$ limit of $1.0 \mathrm{mg} \cdot \mathrm{L}^{-1}$ is usually imposed on industries discharging to surface water to prevent damage to aquatic ecosystems (MOEE, 1994), suggesting technology will be needed to drastically reduce $[\mathrm{P}]$ in greenhouse wastewater.

\footnotetext{
Received for publication 11 Feb. 2015. Accepted for publication 15 Apr. 2015.

We thank the Natural Sciences and Engineering Council of Canada for providing the scholarship to S. Dunets for this project, Mike Dixon for the informative discussion, and David Llewellyn for providing technical support.

${ }^{1}$ To whom reprint requests should be addressed; e-mail yzheng@uoguelph.ca.
}

Phosphate precipitation using lime addition is one of the most basic and widely used methods for $\mathrm{P}$ treatment in other wastewater types (de-Bashan and Bashan, 2004; Pratt et al., 2012), and can achieve $>99 \%$ soluble $P$ removal in greenhouse wastewater (Dunets and Zheng, 2014). Interactions of fine precipitate with organic material cause issues with separation of precipitated $\mathrm{P}$ in other wastewater types (de-Bashan and Bashan, 2004; Pratt et al., 2012; Valsami-Jones, 2001). However, due to the typically low organic (Gagnon et al., 2010; Prystay and Lo, 2001; Saxena and Bassi, 2012) and very high nutrient content of greenhouse wastewater, there is potential to not only efficiently remove but also recover large amounts of $\mathrm{P}$ as largely pure calcium phosphate (Ca-P) precipitate that has great potential to be reused as fertilizer. Recovery is currently a major research interest as $\mathrm{P}$ is a valuable nonrenewable resource (Valsami-Jones, 2001). As greenhouse wastewater contains high concentrations of all plant nutrients, recovered precipitate could be a source of other nutrients (such as $\mathrm{K}, \mathrm{Mg}$, and micronutrients) in addition to $\mathrm{Ca}$ and $\mathrm{P}$ through substitution in the Ca-P mineral structure and formation of other precipitates (Saxena and Bassi, 2012; Yi et al., 2005).

However, potential issues with fine Ca-P precipitate separation and optimizing recovery while simultaneously meeting low
$\mathrm{P}$ limits in a low-organic, high-P wastewater such as greenhouse wastewater have yet to be investigated. Depending on particle size and separation rate of fine precipitate, which may be affected by wastewater composition (such as carbonate and $\mathrm{Mg}$ content; Valsami-Jones 2001), accommodating extended settling time required for full separation may not be efficient. A combined method of precipitation followed by a flocculation step to gather fine precipitate into larger flocs and speedup settling could aid in streamlining the separation and recovery process. Readily available, lowcost biopolymers such as starch (Vandamme et al., 2009), chitosan (Roussy et al., 2004), various types of gum (Gupta and Ako, 2005), and alginate (Renault et al., 2009) are promising flocculant options as they are readily biodegradable and pose no environmental hazard in discharged wastewater.

A combined precipitation/flocculation separation process using lime and a low-cost, biodegradable flocculant must be investigated as a potential optimized $\mathrm{P}$ recovery method specifically suited to greenhouse wastewater. An optimal separation process should reduce total $\mathrm{P}$ in wastewater to low levels $\left(<1 \mathrm{mg} \cdot \mathrm{L}^{-1}\right)$ required to prevent environmental damage, minimize $\mathrm{P}$ separation time, and retrieve a product with a nutrient composition that makes it valuable as a fertilizer. The aim of this study was to evaluate the capacity of different lime/flocculant combinations to meet these criteria by examining separation dynamics in real and model wastewaters of varying composition, as well as analyzing nutrient composition of the retrieved precipitate to determine viability for reuse.

\section{Materials and Methods}

Materials. Powder hydrated lime (Graymont Dolomitic Spray Lime, CAS \#3944523-3; Graymont Dolime Inc., Genoa, $\mathrm{OH}$ ) was used to induce Ca-P precipitation. Flocculation materials investigated were chitosan (448877; Sigma-Aldrich Canada Co., Oakville, ON, Canada), guar gum (PPN4000; Rantec Corporation, Ranchester, WY), and a cationic starch flocculant (Charge +110 ; Cargill Inc., Cedar Rapids, IA), all in solid form. Properties of these flocculants are given in Table 1. Flocculants were prepared as $1 \%(\mathrm{w} / \mathrm{v})$ solutions before addition to wastewater. Chitosan was dissolved by mixing for $12 \mathrm{~h}$ in $1 \%$ acetic acid (Kadouche et al., 2012), starch was dissolved in water by mixing for $30 \mathrm{~min}$ at $80{ }^{\circ} \mathrm{C}$ (Vandamme et al., 2009), and guar gum was dissolved in water at room temperature.

Ca-P precipitation/separation and impact of flocculants. The effectiveness of lime precipitation for $\mathrm{P}$ separation in simulated wastewater of low and high alkalinity, and the effect of flocculants on separation, was investigated. Wastewater solutions were prepared by adding $100 \mathrm{mg} \cdot \mathrm{L}^{-1} \mathrm{PO}_{4}-\mathrm{P}$ and other nutrients at the rates listed in Table 2 to deionized water (low alkalinity) or tap water (high alkalinity) by dissolving $\mathrm{KH}_{2} \mathrm{PO}_{4}$ and 
Table 1. Properties of flocculants.

\begin{tabular}{lcc}
\hline Flocculant & $\begin{array}{c}\text { Molecular } \\
\text { wt }(\mathrm{kDa})\end{array}$ & $\begin{array}{c}\text { Estimated } \\
\text { cost }(\$ / \mathrm{kg})\end{array}$ \\
\hline Chitosan & $190-310$ & $13.00 \mathrm{USD}^{\mathrm{z}}$ \\
Guar gum & $1000-1500$ & $3.52 \mathrm{USD}$ \\
Cationic starch & $1000-2000$ & $0.56 \mathrm{USD}$ \\
\hline
\end{tabular}

${ }^{\mathrm{z} C h i}$ and Cheng, 2006.

Table 2. Nutrient concentration added to simulated wastewater.

\begin{tabular}{lc}
\hline Nutrient & $\operatorname{Concn}^{2}\left(\mathrm{mg} \cdot \mathrm{L}^{-1}\right)$ \\
\hline $\mathrm{PO}_{4}-\mathrm{P}$ & 100 \\
$\mathrm{NO}_{3}{ }^{-}-\mathrm{N}$ & 414 \\
$\mathrm{NH}_{4}{ }^{+}-\mathrm{N}$ & 37.0 \\
$\mathrm{~K}$ & 500 \\
$\mathrm{Ca}$ & 190 \\
$\mathrm{Mg}$ & 93.4 \\
$\mathrm{~B}$ & 0.64 \\
$\mathrm{Cu}$ & 1.61 \\
$\mathrm{Fe}$ & 3.22 \\
$\mathrm{Mn}$ & 1.61 \\
$\mathrm{Mo}$ & 0.48 \\
$\mathrm{Zn}$ & 1.61 \\
\hline
\end{tabular}

${ }^{\text {z }} \mathrm{PO}_{4}-\mathrm{P}$ (phosphate-derived phosphorus) concentration was measured according to the methods listed in the "Analytical Methods" section; addition of other nutrients was estimated from fertilizer composition and addition rate.

Plantex ${ }^{\circledR}$ 14-0-14 Cal Mag Fertilizer (Plant Products Co. Ltd, Brampton, ON, Canada). $\mathrm{P}$ concentration represented a medium to high wastewater $\mathrm{P}$ concentration based on the literature (White, 2013), and other nutrient concentrations were typical of a greenhouse vegetable feeding nutrient solution. Alkalinity of low- and high-alkalinity solutions was 78 and $220 \mathrm{mg} \cdot \mathrm{L}^{-1} \mathrm{CaCO}_{3}$, respectively, representing the extremes of the range of alkalinity reported in greenhouse wastewater $\left(\approx 50-250 \mathrm{mg} \cdot \mathrm{L}^{-1} \mathrm{CaCO}_{3}\right.$; MOE, 2012). Drop-wise addition of $1 \mathrm{M} \mathrm{KOH}$ was used to bring the solutions to an initial $\mathrm{pH}$ of $6.5 \pm 0.1$.

Treatments consisting of a control (lime addition with no flocculant), and chitosan, guar gum, and cationic starch treatments where flocculant was added along with lime, were investigated in low- and high-alkalinity simulated wastewater. For each treatment, $500 \mathrm{~mL}$ of solution was poured into a $600-\mathrm{mL}$ beaker and lime was added under continuous stirring using a jar test apparatus (PB-700 Jartester; Phipps \& Bird, Richmond, VA). Lime addition rate was $0.3 \mathrm{~g} \cdot \mathrm{L}^{-1}$ and 0.55 $\mathrm{g} \cdot \mathrm{L}^{-1}$ for low- and high-alkalinity wastewater, respectively, and was chosen as the amount of lime required to obtain a $\mathrm{pH}$ of around 9.5, as determined in preexperiments. After lime addition, solution was mixed at $160 \mathrm{rpm}$ for $7 \mathrm{~min}$ to allow for dissolution of lime and dispersion of flocculant, followed by 20 min slow mixing at $60 \mathrm{rpm}$ to encourage flocculation (Roussy et al., 2004). Guar gum and cationic starch were added $4 \mathrm{~min}$ after lime addition, whereas chitosan was added 3 min before lime addition, to allow for 3-min dispersion at a $\mathrm{pH}$ optimal for chitosan interaction, as chitosan is insoluble at high pH (Bratskaya et al., 2004). pH of the solution/lime/flocculant mixtures was measured during the slow mixing period. There were three replicates for each treatment.

A flocculant addition rate of $12 \mathrm{mg} \cdot \mathrm{L}^{-1}$ was investigated for each flocculant in lowalkalinity solution. Based on separation results, rates of 2 and $6 \mathrm{mg} \cdot \mathrm{L}^{-1}$ for guar gum and $24 \mathrm{mg} \cdot \mathrm{L}^{-1}$ and $60 \mathrm{mg} \cdot \mathrm{L}^{-1}$ for starch were also tested to determine optimal dose to maximize effectiveness while minimizing cost. Addition rates used for high-alkalinity treatments were based on the lowest dose of each flocculant that maximized $\mathrm{P}$ separation in low alkalinity treatments, and were $12 \mathrm{mg} \cdot \mathrm{L}^{-1}$ for chitosan and guar gum and $24 \mathrm{mg} \cdot \mathrm{L}^{-1}$ for cationic starch.

After mixing, precipitate was allowed to settle and $20 \mathrm{~mL}$ samples of the supernatant were taken after $2 \mathrm{~min}, 10 \mathrm{~min}, 30 \mathrm{~min}$, as well as $1 \mathrm{~h}$ for treatments in which unsettled precipitate was still clearly visible after 30 min. Total P (soluble P + unseparated precipitate) in these supernatant samples was measured to determine separation of $\mathrm{P}$ precipitate over time.

Application of $P$ separation to varied greenhouse wastewater. Effectiveness of precipitation/flocculation in real greenhouse wastewaters of varying composition was evaluated. Greenhouse wastewater samples were collected from three different greenhouses in Southwestern Ontario: a potted begonia greenhouse with a subirrigation system that did not recycle nutrient solution; a campanula greenhouse that continuously recycled nutrient solution; and a sweet pepper and eggplant greenhouse that continuously recycled nutrient solution. $\mathrm{pH}, \mathrm{EC}$, and alkalinity of these wastewaters, and nutrient concentrations in samples filtered at $0.45 \mu \mathrm{m}$, were determined.

A second set of separation experiments was conducted on campanula and pepper/ eggplant wastewater according to the methods of the first experiment, using a lime addition rate required to reach $\mathrm{pH} 9.0$ in each wastewater (determined in preexperiments) and optimal flocculant concentrations determined in the first experiment.

Analysis of retrieved precipitate. The precipitate separated from the pepper and eggplant greenhouse wastewater $(n=3)$ was dried at $50{ }^{\circ} \mathrm{C}$ for $48 \mathrm{~h}$. To determine total nutrient composition, the weighed sample $(0.45 \pm 0.01$ g) was predigested overnight in $3 \mathrm{~mL} \mathrm{HCl}$ $(37 \% \mathrm{w} / \mathrm{v})+9 \mathrm{~mL} \mathrm{HNO}_{3}(68 \% \mathrm{w} / \mathrm{v})$, both trace metal grade, then digested in a Teflon bomb at $120{ }^{\circ} \mathrm{C}$ for $3 \mathrm{~h}$, an adaptation of a conventional aqua regia digesion used by Chen and Ma (2001). Digested solution was diluted to $50 \mathrm{~mL}$ and filtered with a No. 42 Whatman filter. "Plant available P" (or "extractable $\mathrm{P}$ ") in the precipitate was estimated using $2 \%$ citric acid extraction and bicarbonate extraction, using the methods in Faithfull (2002) and Tiessen and Moir (2007), respectively. Extraction was performed using a $0.1 \mathrm{~g}$ precipitate subsample in $30 \mathrm{~mL}$ of bicarbonate or $50 \mathrm{~mL}$ of citric acid, replicated three times for each extraction.

Analytical methods. For determination of total $\mathrm{PO}_{4}-\mathrm{P}$ (suspended precipitate + soluble $\left.\mathrm{P}\right)$ and concentration of other nutrients, samples were acidified to $\mathrm{pH} \approx 2$ using $\mathrm{H}_{2} \mathrm{SO}_{4}$ and filtered through a $0.45-\mu \mathrm{m}$ syringe filter (09-719 F; Thermo Fisher Scientific Inc., Waltham, MA). Samples for determination of soluble $\mathrm{PO}_{4}-\mathrm{P}$ only were not acidified before filtration. [P] was measured using an ultraviolet-1201 Shimadzu spectrophotometer (Shimadzu corporation, Kyoto, Japan) using the ascorbic acid method (APHA, 1998). Concentrations of $\mathrm{K}, \mathrm{Ca}, \mathrm{Mg}, \mathrm{Fe}$, $\mathrm{Zn}, \mathrm{Mn}$, and $\mathrm{Cu}$ were measured using a flame atomic absorption spectrometer (Varian Spectra AA 220; Varian Medical Systems Inc., Palo Alto, CA). Solution pH was measured using an Oakton 300 Series Handheld $\mathrm{pH}$ and Conductivity Meter (Model number 35631-00; Oakton Instruments, Vernon Hills, IL). Calcium carbonate alkalinity was measured using Hach Alkalinity Test Kit Model AL-DT (Hach Company, Mississauga, ON, Canada).

Statistical analysis. Total [P] in supernatant vs. time was plotted for each treatment and area under the curve calculated using GraphPad Prism $^{\circledR} 6$ (GraphPad Software Inc., La Jolla, CA). Area under the curve provided a representation of the rate and magnitude of $P$ separation for each treatment, with a higher area representing less efficient $\mathrm{P}$ separation. The $[\mathrm{P}]$ data point at $2 \mathrm{~min}$ was not included in the calculation as high concentrations obscured effectiveness at later time points. A variance analysis was performed using PROC MIXED in SAS $^{\circledR}$ version 9.3 (SAS institute Inc., Cary, NC), and mean area under the curve compared among treatments using a Tukey's multiple means comparison test. Solution final $\mathrm{pH}$ was included as a covariate, to account for effect of $\mathrm{pH}$ fluctuation between treatments on $\mathrm{P}$ separation. Significance was determined at a type-I error rate of $5 \%(P=0.05)$.

\section{Results and Discussion}

Precipitation/separation of $P$ and effect of flocculant. Lime addition and subsequent precipitate settling without flocculant addition allowed total $[\mathrm{P}]$ in low-alkalinity model wastewater to reduce to $0.72 \mathrm{mg} \cdot \mathrm{L}^{-1}$, slightly below the limit of $1 \mathrm{mg} \cdot \mathrm{L}^{-1}$ enforced for wastewater in Ontario (MOEE, 1994), after an hour of settling (Fig. 1A). Rapid drop in P within the first 10 min was attributed to faster settling of larger precipitate particles/flocs, followed by slower decrease after $10 \mathrm{~min}$ as a result of settling of fine particles. When alkalinity of the model wastewater was increased to a level on the higher end of the range found in greenhouse wastewater, separation rate decreased and total $[\mathrm{P}]$ did not reach the $1 \mathrm{mg} \cdot \mathrm{L}^{-1}$ limit within an hour of settling (Fig. 1B), suggesting potential separation issues are present, particularly at higher alkalinity. For the low-alkalinity model wastewater, concentration of soluble $\mathrm{P}$ over time remained at $<0.15 \mathrm{mg} \cdot \mathrm{L}^{-1}$ (Fig. 1A), confirming residual $\mathrm{P}$ was made up of slowsettling fine precipitate. Significantly higher presence of fine precipitate in high-alkalinity 
wastewater may be due to carbonate interfering with growth of Ca-P crystals to larger sizes (Kapolos and Koutsoukos, 1999).

Because fine precipitate impacted potential of separation to meet low $\mathrm{P}$ limits in a manageable settling time, flocculants were investigated for increasing separation efficiency. Addition of $12 \mathrm{mg} \cdot \mathrm{L}^{-1}$ chitosan slightly but significantly improved settling rate in the low-alkalinity-simulated wastewater (Fig. 1A), but had no effect in the highalkalinity wastewater (Fig. 1B). Higher addition rates were not tested due to questionable economic viability owing to the high, unpredictable cost of chitosan compared with other flocculants.

Guar gum greatly increased settling of suspended $\mathrm{P}$, reducing total $\mathrm{P}$ in the supernatant to $0.25 \mathrm{mg} \cdot \mathrm{L}^{-1}$ within $10 \mathrm{~min}$ in low-alkalinity wastewater (Fig. 1A). Guar gum addition greatly reduced the higher supernatant $\mathrm{P}$ levels in high-alkalinity wastewater to $0.31 \mathrm{mg} \cdot \mathrm{L}^{-1}$ after 10 min (Fig. 1B), comparable to P levels achieved in the low-alkalinity wastewater. Because of the high effectiveness of guar gum at an addition rate of $12 \mathrm{mg} \cdot \mathrm{L}^{-1}$, the potential to use lower addition rates to reduce treatment costs was investigated. Effectiveness at a concentration of $2 \mathrm{mg} \cdot \mathrm{L}^{-1}$ was greatly reduced, but a concentration of $6 \mathrm{mg} \cdot \mathrm{L}^{-1}$ provided effectiveness comparable to that of the $12 \mathrm{mg} \cdot \mathrm{L}^{-1}$ if at least 10 min of settling was allowed (Fig. 2A).

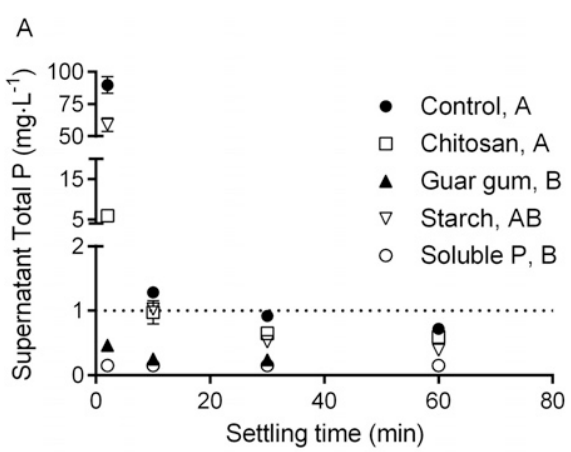

B

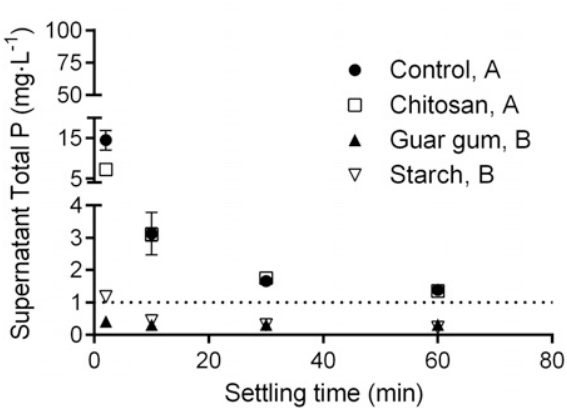

Fig. 1. Total phosphorus (P) separation over settling time after lime addition with and without addition of various flocculants in (A) low-alkalinity-simulated wastewater and (B) high-alkalinity-simulated wastewater. Data are means \pm SE $(n=3)$. Differences between letters following treatment labels in the legend indicate that area under the curve values of these treatments were significantly different at $P<0.05$. "Soluble $\mathrm{P}$ " in $(\mathbf{A})$ refers to the soluble fraction of total $\mathrm{P}$ in the supernatant.
Cationic starch at a concentration of 12 $\mathrm{mg} \cdot \mathrm{L}^{-1}$ had a small but significant effect on $\mathrm{P}$ separation in low-alkalinity wastewater (Fig. 1A). Because of its low cost, effectiveness at higher concentrations was investigated. An addition rate of $60 \mathrm{mg} \cdot \mathrm{L}^{-1}$ reduced total $[\mathrm{P}]$ to as low as $<0.15 \mathrm{mg} \cdot \mathrm{L}^{-1}$ within $10 \mathrm{~min}$ of settling (Fig. 2B). However, a more economically feasible cationic starch concentration of $24 \mathrm{mg} \cdot \mathrm{L}^{-1}$ reduced $[\mathrm{P}]$ to $0.31 \mathrm{mg} \cdot \mathrm{L}^{-1}$ after 30 min, comparable to effectiveness of guar gum, and was designated as the "optimal" rate. Addition of $24 \mathrm{mg} \cdot \mathrm{L}^{-1}$ cationic starch to high alkalinity wastewater provided $\mathrm{P}$ separation comparable to that of guar gum (Fig. 1B).

Long-chain polysaccharide flocculants improve settling of fine $\mathrm{Ca}-\mathrm{P}$ precipitate by adsorbing to the surface of more than one particle and forming polymer bridges

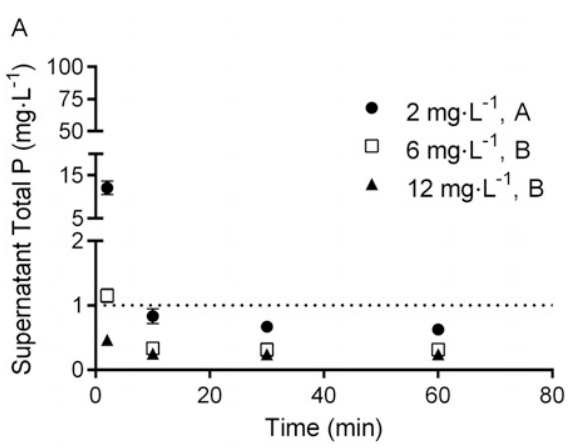

B

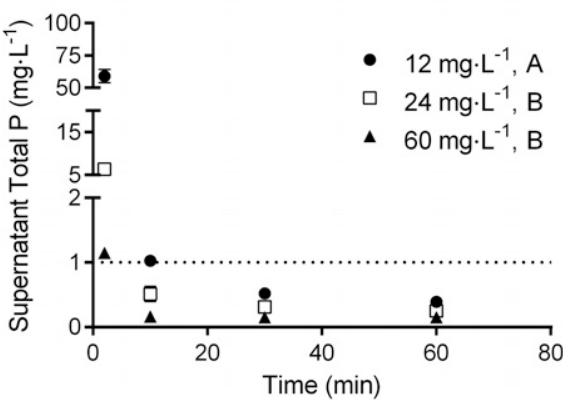

Fig. 2. Total phosphorus separation over settling time after lime addition at different flocculant addition rates for (A) guar gum and (B) cationic starch. Data are means $\pm \operatorname{SE}(n=3)$. Differences between letters following treatment labels in the legend indicate that area under the curve values of these treatments were significantly different at $P<0.05$.

Table 3. Properties of sampled greenhouse wastewater. Data are means $\pm \operatorname{SE}(n=3)$ of three representative samples of a larger sample container.

\begin{tabular}{lccc}
\hline & \multicolumn{3}{c}{ Concn $\left(\mathrm{mg} \cdot \mathrm{L}^{-1}\right)$} \\
\cline { 2 - 4 } Nutrient & Begonia & Campanula & Pepper/eggplant \\
\hline $\mathrm{PO}_{4}-\mathrm{P}$ & $0.50 \pm 0.01$ & $13.4 \pm 0.09$ & $50.7 \pm 0.69$ \\
$\mathrm{~K}$ & $8.60 \pm 0.12$ & $74.0 \pm 1.48$ & $185 \pm 7.72$ \\
$\mathrm{Ca}$ & $93.0 \pm 0.30$ & $36.4 \pm 0.90$ & $119 \pm 7.79$ \\
$\mathrm{Mg}$ & $37.7 \pm 1.33$ & $10.2 \pm 0.15$ & $28.5 \pm 1.18$ \\
$\mathrm{Cu}$ & $0.007 \pm 0.003$ & $1.10 \pm 0.02$ & $0.04 \pm 0.00$ \\
$\mathrm{Fe}$ & $0.01 \pm 0.003$ & $0.49 \pm 0.01$ & $1.22 \pm 0.04$ \\
$\mathrm{Mn}$ & $0.02 \pm 0.00$ & $0.26 \pm 0.01$ & $0.04 \pm 0.00$ \\
$\mathrm{Zn}$ & $0.04 \pm 0.003$ & $0.49 \pm 0.01$ & $0.35 \pm 0.02$ \\
$\mathrm{pH}$ & 8.34 & 4.31 & 6.31 \\
Alkalinity $\left(\mathrm{as}_{\mathrm{CaCO}}\right)$ & $184 \pm 7.35$ & 0 & $42.3 \pm 2.34$ \\
\hline
\end{tabular}
larger agglomerations or "flocs" with improved settling speed (Tripathy and Ranjan De, 2006). High effectiveness of guar gum despite its lack of charge suggested that, unlike in some treatment situations where particle charge attracts an obstructive layer of oppositely charged ions (Renault et al., 2009), neutralization of charge on the precipitate surface was not necessary to induce particles to make contact with each other and form flocs. The high effectiveness of guar gum and cationic starch can therefore be attributed primarily to long polymer chain length as indicated by high-molecular weight (Tan et al., 2014), compared with chitosan, which typically has a molecular weight $<300$ $\mathrm{kDa}$ (Tan et al., 2014), as well as potentially to side branching on the polymer chain (Singh et al., 2000). It is also likely the effectiveness of chitosan was further diminished due to its low solubility at this high $\mathrm{pH}$ (Bratskaya et al., 2004).

These results suggest slow-settling precipitate can create issues with reducing total $\mathrm{P}$ in wastewater below the $0.5-1 \mathrm{mg} \cdot \mathrm{L}^{-1}$ limits enforced for many point-source polluters in Canada (MOEE, 1994), particularly in wastewater with high $\left(>200 \mathrm{mg} \cdot \mathrm{L}^{-1}\right.$ $\mathrm{CaCO}_{3}$ ) alkalinity, and that these issues may be overcome by using a combined precipitation/flocculation process to remove precipitate that would otherwise remain suspended in discharged wastewater. P concentration in surface water should be as low as $0.03 \mathrm{mg} \cdot \mathrm{L}^{-1}$ to prevent damage to aquatic ecosystems (CCME, 2004), suggesting minimizing total $\mathrm{P}$ released to the environment is ideal. Addition of a flocculation step also allows maximum $\mathrm{P}$ separation to occur within a shorter time period (10-30 min settling), which would simplify system design by removing the need to accommodate an extended settling time. However, the high variability of greenhouse wastewater composition may affect this separation process, and its effectiveness must therefore be tested in real greenhouse wastewater.

Application to greenhouse wastewater. Compositions of the three greenhouse wastewaters sampled for this study demonstrated high variability in $\mathrm{pH}$, alkalinity, and nutrient composition, with the vegetable greenhouse wastewater showing the highest [P] (Table 3). $[\mathrm{P}]$ in the begonia wastewater was already between them, gathering fine precipitate into 
$<0.5 \mathrm{mg} \cdot \mathrm{L}^{-1}$, suggesting additional $\mathrm{P}$ treatment would not be worthwhile. While alkalinity of the other two wastewaters was within the range reported in southern Ontario greenhouses (MOE, 2012), the campanula wastewater exhibited a $\mathrm{pH}$ and alkalinity far below the expected range. All wastewaters contained very little visible suspended material (low turbidity from suspended organic material), as is commonly reported for greenhouse wastewater (Gagnon et al., 2010; Prystay and Lo, 2001). Despite high variation, overall, nutrient concentrations of these wastewaters were within the ranges reported among southern Ontario greenhouses (MOE, 2012), suggesting these wastewaters provide a good representation of greenhouse wastewater composition for testing treatment requirements.

The amount of lime required to obtain a $\mathrm{pH}$ of 9 in vegetable wastewater was 278 $\mathrm{mg} \cdot \mathrm{L}^{-1}$, as determined via interpolation from a graph of lime addition vs. $\mathrm{pH}$. Considering the molecular weight of the lime used was $132.41 \mathrm{~g} \cdot \mathrm{mol}^{-1}$, this is a lime addition: [P] molar ratio of 1.3 , which is close to the guideline of 1.5 determined for precipitation in greenhouse wastewater (Dunets and Zheng, 2014). At this lime addition rate, the precipitation step alone was able to reduce total $[\mathrm{P}]$ in the vegetable wastewater to 0.81 $\mathrm{mg} \cdot \mathrm{L}^{-1}$ after $1 \mathrm{~h}$ of settling (Fig. 3A). It should be noted that this lime addition rate resulted in a wastewater $\mathrm{pH}$ closer to 9.5 when used in the main experiment. Addition of flocculation with guar gum or cationic starch significantly reduced total $[\mathrm{P}]$ remaining to $<0.3 \mathrm{mg} \cdot \mathrm{L}^{-1}$, within a $10 \mathrm{~min}$ settling time, although chitosan had no effect.

Lime requirement for campanula wastewater was found to be $63 \mathrm{mg} \cdot \mathrm{L}^{-1}$. Lime requirement for vegetable wastewater was about four times that of campanula, similar to the ratio of $[\mathrm{P}]$ in the two wastewaters, and was therefore proportional to $[\mathrm{P}]$, as was demonstrated by Dunets and Zheng (2014). Although precipitation at the determined lime addition rate greatly reduced $[\mathrm{P}]$ in campanula wastewater, it was not reduced below $1 \mathrm{mg} \cdot \mathrm{L}^{-1}$ (Fig. 3B). Overall P separation in this wastewater was not greatly improved by any of the flocculants investigated. Increasing lime addition rate to a lime: [P] molar ratio of 1.4 (compared with 1.1), resulting in a $\mathrm{pH}$ of 9.25 , allowed total $\mathrm{P}$ to reduce to $0.95 \mathrm{mg} \cdot \mathrm{L}^{-1}$ after $1 \mathrm{~h}$ settling, but guar gum addition continued to have no effect (Fig. 3B).

The lack of effect of guar gum and cationic starch on separation in the campanula wastewater, in contrast to effectiveness in the vegetable wastewater, is likely a result of the very low alkalinity of the campanula wastewater causing decreased formation of slowsettling fine precipitate. High $\mathrm{P}$ remaining in the campanula wastewater is likely therefore mainly in the soluble form. High soluble $\mathrm{P}$ despite high lime addition (Fig. 3B) could be attributed to the slightly lower final $\mathrm{pH}$ achieved in the campanula wastewater compared with the vegetable wastewater. It should be noted, however, that the vegetable wastewater also demonstrated low alkalinity in comparison with the roughly $50-250 \mathrm{mg} \cdot \mathrm{L}^{-1}$ $\mathrm{CaCO}_{3}$ range reported in greenhouses around Leamington, Ontario (MOE, 2012), suggesting that addition of a flocculant will have at least some benefit in most wastewaters.

The discrepancy between these wastewaters suggests that treatment needs will not be consistent across systems. As demonstrated by the begonia wastewater, $\mathrm{P}$ separation and recovery is not worthwhile for certain greenhouse systems producing low-P $\left(<1 \mathrm{mg} \cdot \mathrm{L}^{-1}\right)$ wastewater. While precipitation was shown to be effective for both the campanula and vegetable wastewaters despite highly divergent composition, effectiveness for reaching a $\mathrm{P}$ limit of $1 \mathrm{mg} \cdot \mathrm{L}^{-1}$ for very-low-alkalinity wastewater was highly dependent on optimal lime addition rate and $\mathrm{pH}$ being reached, which seemed to require a $\mathrm{pH}$ closer to 9.5 . When treating wastewater of very low alkalinity, addition of a flocculation step may be unnecessary, suggesting this step should only be introduced if abundance of slow-settling precipitate appears to be an issue in the treatment system. In the more common event that wastewater alkalinity creates slowsettling precipitate, low-cost flocculants such as guar gum or cationic starch can be added at doses of $12 \mathrm{mg} \cdot \mathrm{L}^{-1}$ or $24 \cdot \mathrm{mg} \cdot \mathrm{L}^{-1}$, respectively, to overcome this issue.

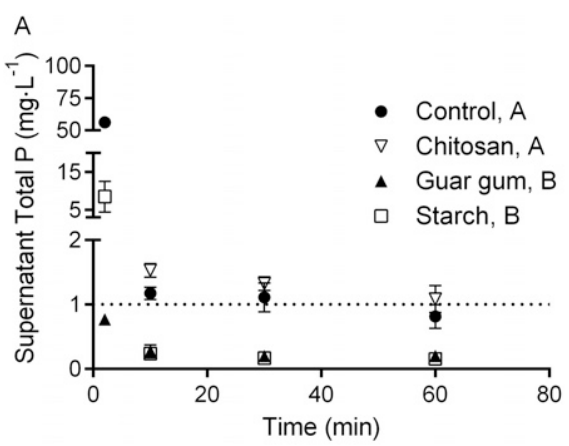

B

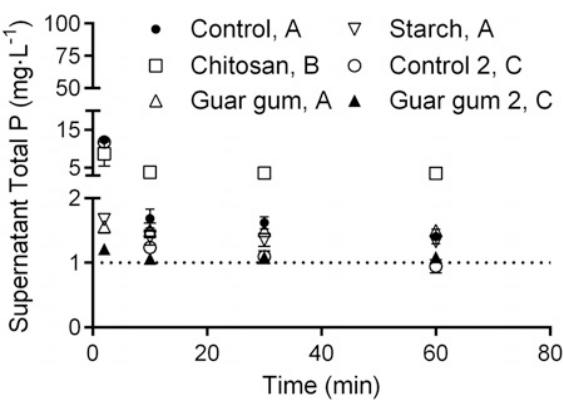

Fig. 3. Total phosphorus (P) separation over settling time after lime addition with and without addition of various flocculants in (A) vegetable wastewater and (B) campanula wastewater. Data are means $\pm \operatorname{SE}(n=3)$. Control 2 and Guar gum 2 indicate treatments where lime was added at a lime: $P$ molar ratio of 1.4, compared with 1.1 in the other treatments. Differences between letters following treatment labels in the legend indicate that area under the curve values of these treatments were significantly different at $P<0.05$.
Nutrient composition of recovered precipitate. The precipitate recovered from the vegetable wastewater had high $\mathrm{P}$ content, as well as high levels of $\mathrm{Ca}, \mathrm{Mg}$, and $\mathrm{K}$, and significant amounts of the micronutrients $\mathrm{Fe}$ and $\mathrm{Zn}$ (Table 4). P content was not as high as that reported in some $\mathrm{P}$ precipitates recovered from wastewater treatment (Bauer et al., 2007; Fernandes et al., 2012; Yi et al., 2005). This may be due to a combination of lower $\mathrm{P}$ concentrations in the vegetable wastewater compared to the wastewaters used in some of these studies, as well as the high $\mathrm{pH}$ induced $(>9)$ to encourage precipitation, as at very high $\mathrm{pH}$ other calcium compounds such as calcium carbonate will become a larger fraction of the precipitate (Yi et al., 2005). $\mathrm{K}$ and $\mathrm{Mg}$ levels were unexpectedly higher than those reported for other recovered precipitates (Bauer et al., 2007; Fernandes et al., 2012), which suggested some formation of K-struvite $\left(\mathrm{MgKPO}_{4} \cdot 6 \mathrm{H}_{2} \mathrm{O}\right)$, to a greater extent than previously reported in greenhouse wastewater (Yi et al., 2005), although Yi et al. (2005) used $\mathrm{NaOH}$ as opposed to dolomitic lime. The Ca:P molar ratio of 1.25 was lower than that of amorphous calcium phosphate $\left[\mathrm{Ca}_{3}\right.$ $\left.\left(\mathrm{PO}_{4}\right)_{2}\right]$, the most likely $\mathrm{Ca}-\mathrm{P}$ product in this context (Fernandes et al., 2012), which is likely the result of the presence of other metals such as $\mathrm{Mg}$ and $\mathrm{K}$ in the precipitate structure (Valsami-Jones, 2001; Yi et al., 2005). Precipitate composition will vary with wastewater composition, and it is likely that precipitate recovered from greenhouse wastewater with higher [P] than this vegetable wastewater (as is often reported in greenhouse systems; White, 2013) will exhibit higher P content (Yi et al., 2005).

A high proportion of total $\mathrm{P}$ was easily extracted using bicarbonate or, to a greater extent, citric acid (Table 4), suggesting much of the $\mathrm{P}$ will become available to plants in varied growing media conditions (Faithfull, 2002; Tiessen and Moir, 2007), and that the precipitate is therefore promising for use as a fertilizer in its original form. High levels of a number of plant nutrients suggested the precipitate can be an important source of nutrients for small-scale applications such as container production, green roofs, etc. Further research involving application of precipitate products retrieved from greenhouse wastewater treatment to plant production is needed.

Table 4. Nutrient composition of precipitate recovered from vegetable greenhouse wastewater. Data are means $\pm \mathrm{SE}(n=3)$.

\begin{tabular}{lc}
\hline Nutrient & $\mathrm{g} \cdot \mathrm{kg}^{-1}$ \\
\hline $\mathrm{P}$ (total) & $57.4 \pm 3.39$ \\
$\mathrm{P}$ (citric acid extract) & $52.1 \pm 1.33$ \\
$\mathrm{P}$ (bicarbonate extract) & $36.4 \pm 0.70$ \\
$\mathrm{~K}$ & $52.9 \pm 3.44$ \\
$\mathrm{Ca}$ & $92.7 \pm 5.07$ \\
$\mathrm{Mg}$ & $57.6 \pm 1.56$ \\
$\mathrm{Fe}$ & $1.70 \pm 0.10$ \\
$\mathrm{Mn}$ & $0.05 \pm 0.001$ \\
$\mathrm{Zn}$ & $0.18 \pm 0.01$ \\
$\mathrm{Cu}$ & $0.03 \pm 0.001$
\end{tabular}


Potential for large-scale application. Overall, precipitation via lime addition was effective for P removal in wastewaters of disparate composition, and a combined precipitation/flocculation process could be used to optimize this method for efficiently meeting low P limits while simultaneously recovering high concentrations of $\mathrm{P}$ in a reuseable form. At a lime cost of $\$ 0.40$ $\mathrm{USD} / \mathrm{kg}$ (as determined from local supplier), cost of lime treatment of the vegetable wastewater and campanula wastewater would be only $\$ 0.12 \mathrm{USD} / \mathrm{m}^{3}$ wastewater treated and $\$ 0.03 \mathrm{USD} / \mathrm{m}^{3}$, respectively. Adding guar gum or cationic starch would only increase cost of wastewater treatment by $\$ 0.04 \mathrm{USD} / \mathrm{m}^{3}$ and $\$ 0.02 \mathrm{USD} / \mathrm{m}^{3}$, respectively.

Research of application of this technology at a full-scale in an actual greenhouse facility is needed to properly address engineering questions. This precipitation/flocculation $\mathrm{P}$ separation could be achieved in a stirred reactor. The combined lime mixing, flocculation, and precipitate settling process required around an hour, and different mixing rates for each step, suggesting a more advanced multitank systems may need to be considered for systems where a relatively large amount of wastewater must be treated daily. Another potential issue is that biodegradable flocculants degrade (and therefore lose effectiveness) rapidly in water, creating issues with mixing and storing these flocculants before dosing (Tripathy and Ranjan De, 2006). As such guar gum may be the most viable option as it can be quickly dissolved in water at room temperature. Challenges with dewatering and drying of the precipitate "sludge" must also be addressed, although the precipitate flocs formed from this process appeared dense and, by qualitative observation, occupied around $10 \%$ of total wastewater volume, suggesting the volume of sludge produced will be low.

Potential regulatory issues with high-pH wastewater must also be considered, as a regulatory $\mathrm{pH}$ limit of 9.5 is in place for wastewater in Ontario (Canadian Environmental Protection Act, 1995). While final pH of treatments tended to be slightly higher than this limit, $\mathrm{pH}$ around 9 has been found to be sufficient to achieve soluble $\mathrm{P}$ concentrations $<1 \mathrm{mg} \cdot \mathrm{L}^{-1}$ (Dunets and Zheng, 2014). As well, effluent $\mathrm{pH}$ could be further decreased before discharging by leaving the solution open to the air (i.e., in a pond) so that $\mathrm{CO}_{2}$ dissolution may neutralize it (Vanotti et al., 2007), or, if this is not sufficient, adding small amounts of acid or running through acidic materials such as peatmoss.

Because of likely variation in precipitation product between facilities, and the low quantity of product produced compared with a typical wastewater treatment plant, it is unlikely the precipitate could be marketed as a value-added product. However, as the main goal is high $P$ removal, potential for reuse of the product need only be an added benefit from a resource-management standpoint (considering the status of $\mathrm{P}$ as a nonrenewable resource), as well as a means of easily offloading a treatment "waste material." Specific users for this recovered precipitate would need to be identified on introduction of this treatment at a full scale.

\section{Conclusion}

Precipitation using hydrated lime could provide a simple method for recovering nutrients from greenhouse wastewater in a reuseable form while simultaneously meeting very low P limits, but the fine grain size of precipitate may complicate efficient separation. The aim of this study was to evaluate precipitation for efficient $P$ separation and nutrient recovery, and the potential to optimize this process by adding a flocculation step. Fine precipitate created issues with slow separation, particularly in wastewater with high alkalinity, but guar gum and cationic starch flocculation rapidly separated suspended $\mathrm{P}$ at addition rates that would be of low cost. Precipitation reduced $\mathrm{P}$ concentrations to below $1 \mathrm{mg} \cdot \mathrm{L}^{-1}$ in greenhouse wastewaters of differing composition, but an additional flocculation step only improved $\mathrm{P}$ separation in the vegetable greenhouse wastewater, suggesting treatment needs will vary between systems. The recovered precipitate contained $57.4 \mathrm{~g} \cdot \mathrm{kg}^{-1} \mathrm{P}$, as well as significant amounts of $\mathrm{Ca}, \mathrm{K}, \mathrm{Mg}, \mathrm{Fe}$, and $\mathrm{Zn}$, indicating it has promise for reuse as a recycled nutrient source for plant production. Overall, a precipitation/ flocculation process could provide an optimized means of meeting very low $\mathrm{P}$ limits while simultaneously recovering $\mathrm{P}$ and other nutrients. Further research on engineering challenges involved in implementation of a fullsized system in a real greenhouse operation is needed.

\section{Literature Cited}

American Public Health Association (APHA). 1998. Standard methods for the examination of water and wastewater. 19th ed. American Public Health Association/American Water Works Association/Water Environment Federation, Washington, D.C.

Bauer, P.J., A.A. Szogi, and M.B. Vanotti. 2007. Agronomic effectiveness of calcium phosphate recovered from liquid swine manure. Agron. J. 99:1352-1356.

Bratskaya, S.Y., S. Schwarz, and D. Chervonetsky. 2004. Comparative study of humic acids flocculation with chitosan hydrochloride and chitosan glutamate. Water Res. 38:2955-2961.

Canadian Council of Ministers of the Environment (CCME). 2004. Canadian water quality guidelines for the protection of aquatic life: Phosphorus: Canadian Guidance Framework for the Management of Freshwater Systems. In: Canadian environmental quality guidelines. Canadian Council of Ministers of the Environment, Winnipeg, Canada.

Canadian Environmental Protection Act. 1995. Ontario regulation 63/95. 7 Apr. 2015. <http:// www.e-laws.gov.on.ca/html/regs/english/elaws_ regs 950063 e.htm\#BK29>.

Chen, M. and L.Q. Ma. 2001. Comparison of three aqua regia digestion methods for twenty Florida soils. Soil Sci. Soc. Amer. J. 65:491-499.
Chi, F.H. and W.P. Cheng. 2006. Use of chitosan as coagulant to treat wastewater from milk processing plant. J. Polym. Environ. 14:411-417.

de-Bashan, L.E. and Y. Bashan. 2004. Recent advances in removing phosphorus from wastewater and its future use as fertilizer (19972003). Water Res. 38:4222-4246.

Dunets, S.C. and Y. Zheng. 2014. Removal of phosphate from greenhouse wastewater using hydrated lime. Environ. Technol. 35:2852-2862.

Faithfull, N.T. 2002. Methods in agricultural chemical analysis: A practical handbook. CABI Publishing, New York, NY.

Fernandes, G.W., A. Kunz, R.L.R. Steinmetz, A Szogi, M. Vanotti, E.M. Flores, and V.L. Dressler. 2012. Chemical phosphorus removal: A clean strategy for piggery wastewater management in Brazil. Environ. Technol. 33:16771683.

Gagnon, V., G. Maltais-Landry, J. Puigagut, F. Chazarenc, and J. Brisson. 2010. Treatment of hydroponics wastewater using constructed wetlands in winter conditions. Water Air Soil Pollut. 212:483-490.

Gupta, B.S. and J.E. Ako. 2005. Application of guar gum as a flocculant aid in food processing and potable water treatment. Eur. Food Res. Technol. 221:746-751.

Kadouche, S., H. Lounici, K. Benaoumeur, N. Drouiche, M. Hadioui, and P. Sharrock. 2012. Enhancement of sedimentation velocity of heavy metals loaded hydroxyapatite using chitosan extracted from shrimp waste. J. Polym. Environ. 20:848-857.

Kapolos, J. and P.G. Koutsoukos. 1999. Formation of calcium phosphates in aqueous solutions in the presence of carbonate ions. Langmuir 15:6557-6562.

Ontario Greenhouse Vegetable Growers (OGVG). 2012. Greenhouse Vegetable Growers committed to supporting clean, healthy Great Lakes. 27 Jan. 2015. <http://www.ontariogreenhouse. com/default/assets/File/2012\%20May\%209\% 20OGVG\%20Media\%20Statement.pdf>.

Ontario Ministry of the Environment (MOE). 2012. An analysis of nutrients and select metals within wastewater (pond discharges) (20072011). In: Greenhouse operations in and around Leamington, Ontario. Queen's Printer for Ontario, Toronto, Canada.

Ontario Ministry of the Environment and Energy (MOEE). 1994. Guideline F-8: Provision and operation of phosphorus removal facilities at municipal, institutional and private sewage treatment works. 27 Jan. 2015. <http://www. ontario.ca/environment-and-energy/f-8-provisionand-operation-phosphorus-removal-facilitiesmunicipal>.

Pratt, C., S.A. Parsons, A. Soares, and B.D. Martin . 2012. Biologically and chemically mediated adsorption and precipitation of phosphorus from wastewater. Curr. Opin. Biotechnol. 23: 890-896.

Prystay, W. and K.V. Lo. 2001. Treatment of greenhouse wastewater using constructed wetlands. J. Environ. Sci. Health B 36:341-353.

Renault, F., B. Sancey, P.M. Badot, and G. Crini. 2009. Chitosan for coagulation/flocculation process: An eco-friendly approach. Eur. Polym. J. 45:1337-1348.

Roussy, J., M. Van Vooren, and E. Guibal. 2004. Chitosan for the coagulation and flocculation of mineral colloids. J. Dispersion. Sci. Technol. 25:663-677.

Saxena, P. and A. Bassi. 2012. Removal of nutrients from hydroponic greenhouse effluent by alkali precipitation and algae cultivation method. $\mathrm{J}$. Chem. Technol. Biotechnol. 88:858-863. 
Singh, R.P., G.P. Karmakar, S.K. Rath, N.C. Karmakar, S.R. Pandey, T. Tripathi, J. Panda, K. Kannan, S.K. Jain, and N.T. Lan. 2000. Biodegradable drag reducing agents and flocculants based on polysaccharides: Materials and applications. Polym. Eng. Sci. 40:46-60.

Tan, X., G. Zhang, A.H. Reed, and Y. Furukawa. 2014. Flocculation and particle size analysis of expansive clay sediments affected by biological, chemical, and hydrodynamic factors. Ocean Dyn. 64:143-157.

Tiessen, H. and J.O. Moir. 2007. Characterization of available $\mathrm{P}$ by sequential extraction. In: Carter, M.R. and E.G. Gregorich (eds.). Soil sampling and methods of analysis. 2nd ed. CRC Press, Boca Raton, FL.

Tripathy, T. and B. Ranjan De. 2006. Flocculation: A new way to treat the waste water. J. Physiol. Sci. 19:93-127.

Valsami-Jones, E. 2001. Mineralogical controls on phosphorous recovery from wastewaters. Mineral. Mag. 65:611-620.

Vandamme, D., I. Foubert, B. Meesschaert, and K. Muylaert. 2009. Flocculation of microalgae using cationic starch. J. Appl. Phycol. 22:525530.

Vanotti, M.B., A.A. Szogi, P.G. Hunt, P.D. Millner, and F.J. Humenik. 2007. Development of an environmentally superior treatment system to replace anaerobic swine lagoons in the USA. Bioresour. Technol. 98:3184-3194.

Vymazal, J. 2007. Removal of nutrients in various types of constructed wetlands. Sci. Total Environ. 380:65-78.

Yi, W., K.V. Lo, D.S. Mavinic, P.H. Liao, and F. Koch. 2005. The effects of magnesium and ammonium additions on phosphate recovery from greenhouse wastewater. J. Environ. Sci. Health B 40:363-374.

White, S.A. 2013. Wetland technologies for nursery and greenhouse compliance with nutrient regulations. HortScience 48:1103-1108. 